\title{
Toponímia e memória: uma proposta de atividade para as aulas de Língua Portuguesa no Ensino Médio
}

\author{
Toponymy and memory: a proposal of activity for portuguese language classes in high \\ school
}

\author{
Alexandre Melo de Sousa \\ Universidade Federal do Acre \\ Rio Branco, Acre, Brasil \\ Ana Paula Teixeira Gouveia \\ Universidade Federal do Acre \\ Rio Branco, Acre, Brasil
}

\begin{abstract}
Resumo: A Toponímia se ocupa do estudo dos nomes próprios de lugares, em especial, dos aspectos da motivação e do significado dos designativos. Trazemos considerações sobre o caráter interdisciplinar da Toponímia. A interdisciplinaridade não se encontra enclausurada em um conceito, mas em posturas diante do processo de ensino-aprendizagem que procurem proporcionar encontros produtivos entre as disciplinas, as teorias, as práticas e, sobretudo, entre as pessoas. Dessa forma, apresentamos uma proposta de atividade para as aulas de língua portuguesa do Ensino Médio que dialoga com a Toponímia e com a perspectiva da memória oral, na intenção de dar abertura para a contemplação de um gênero textual ligado à linguagem cotidiana de pessoas de diversas ocupações sociais. A relação entre Toponímia e memória pode proporcionar uma aproximação entre alunos e comunidade, como preconiza as Orientações Curriculares para o Ensino Médio, uma interação que envolva respeito pelo outro, trabalho em equipe, dinamicidade na discussão de teoria e prática e, sobretudo, um gênero textual oral (a narrativa da memória) sobre o qual irá discutir a língua a partir dos topônimos.
\end{abstract}

Palavras-chaves: Toponímia. Memória. Interdisciplinaridade. Ensino Médio.

\begin{abstract}
Toponymy studies the place names, in special, the aspects of motivation and meaning of these names. We make considerations about the interdisciplinarity of Toponymy. Interdisciplinarity is not in a framed concept, but it is an attitude faced with teaching-learning process that has a focus on establishing a relation among the fields of knowledge and debate what is possible to produce, in order to create dialogues among disciplines, theories, practices and, most of all, among people. This paper is a proposal of activity for Portuguese language classes in High School based on the relation between Toponymy and memory. It aims to contemplate a textual genre (oral narratives) that has a connection with everyday language performed by people who has different social occupations. The relation between Toponymy and memory can produce a relation of respect, interaction, and dynamicity between students and the people who will be part of this process. This attitude and proposal agrees with the Curricular Orientations for High School.
\end{abstract}

Keywords: Toponymy. Memory. Interdisciplinarity. High School.

* Doutor em Lingu stica. Prof ssor permanente do Programa de Pós-Graduação em Letras: Linguagem e Identidade - PPGLI, e do Mestrado Profissional em Letras - PROFLETRAS. Pesquisador nas áreas de Lexicologia e Toponímia brasileira. Email: alexlinguista@gmail.com.

** Mestre em Letras: Linguagem e Identidade. Pesquisadora Vinculada ao Núcleo de Pesquisa e Extensão em Ambiente, Socioeconomia e Agroecologia - NUPEAS, da Universidade Federal do Amazonas - UFAM. Bolsista da Fundação de Amparo à Pesquisa do Estado do Amazonas FAPEAM. Email: aptgouveia@gmail.com. 


\title{
1 INTRODUÇÃO
}

A Toponímia, disciplina ligada aos estudos linguísticos que se ocupa dos nomes próprios de lugares, em especial, aos aspectos da motivação e do significado dos designativos, pode se apresentar como um campo de estudo propício para atividades em aulas de Língua Portuguesa para o Ensino Médio, especialmente em relação à interdisciplinaridade. Trazemos, então, considerações sobre o caráter interdisciplinar da Toponímia bem como uma proposta de atividade para o Ensino Médio que incorpore a teoria dessa disciplina, trazendo também a perspectiva da memória oral, na intenção de dar abertura para a contemplação de um gênero textual que está ligado à linguagem cotidiana de pessoas de diversas ocupações sociais.

Dessa forma, já que as Orientações Curriculares para o Ensino Médio consideram que "[...] o papel da disciplina Língua Portuguesa é o de possibilitar, por procedimentos sistemáticos, o desenvolvimento das ações de produção de linguagem em diferentes situações de interação [...]" (BRASIL, 2006, p. 27), consideramos a Toponímia como um campo de estudo capaz de corresponder a essa expectativa, pois é uma área que dialoga com outras disciplinas como a Antropologia, a História e a Geografia, por exemplo, trazendo uma multiplicidade de olhares no que se refere aos nomes dos lugares.

Para entendermos o universo desta proposta, comecemos por compreender qual o sentido da interdisciplinaridade que permeia o documento Orientações Curriculares Para o Ensino Médio. Os pesquisadores que têm a interdisciplinaridade como objeto de estudo acordam que não há como defini-la prontamente, pois:

\begin{abstract}
Mais importante do que defini-la, porque o próprio ato de definir estabelece barreiras, é refletir sobre as atitudes que se constituem como interdisciplinares: atitude de humildade diante dos limites do saber próprio e do próprio saber, sem deixar que ela se torne um limite; a atitude de espera diante do já estabelecido para que a dúvida apareça e o novo germine; a atitude do deslumbramento ante a possibilidade de superar outros desafios; a atitude de respeito ao olhar o velho como novo, ao olhar o outro e reconhecê-lo, reconhecendo-se; a atitude de cooperação que conduz às parcerias, às trocas, aos encontros, mais das pessoas que das disciplinas, que propiciam as transformações, razão de ser da interdisciplinaridade. Mais que um fazer, é paixão por aprender, compartilhar e ir além [...] (TRINDADE, 2008, p. 73).
\end{abstract}

Então, segundo Trindade (2006), a interdisciplinaridade não se encontra enclausurada em um conceito, mas em posturas diante do processo de ensinoaprendizagem que procurem relacionar campos do saber e discutir o que pode ser produzido a partir disso da melhor forma, objetivando proporcionar encontros produtivos entre as disciplinas, teorias, práticas e, sobretudo, entre pessoas.

A interdisciplinaridade, para Japiassu (1976), constitui, na verdade, uma postura diante do ensino:

[...] Podemos dizer que nos reconhecemos diante de um empreendimento interdisciplinar todas as vezes em que ele conseguir incorporar os resultados de várias especialidades, que tomar de empréstimo a outras disciplinas certos instrumentos e técnicas metodológicos, 
fazendo uso dos esquemas conceituais e das análises que se encontram nos diversos ramos do saber, a fim de fazê-los integrarem e convergirem [...] (JAPIASSU, 1976, p. 75).

Considerando a contribuição de Japiassu (1976), reputamos a ideologia sobre a qual se constrói a interdisciplinaridade proposta nas Orientações Curriculares Para o Ensino Médio bem como sua importância no tocante à valorização de atividades que conduzam o aluno a uma proximidade mais considerável das diversas linguagens do cotidiano:

A assunção de tal postura pode, certamente, propiciar que o aluno tenha uma visão/concepção do objeto mais plástica, mais crítica, mais rica e, portanto, mais complexa. Suponhamos que o objeto de ensino em questão sejam as narrativas do mundo cotidiano. Dada a amplitude do tema, podem-se propor inúmeros recortes, definidos à luz do propósito que se quer alcançar [...] (BRASIL, 2006, p. 27).

É exatamente no destaque ao trecho "narrativas do mundo cotidiano" (BRASIL, 2006, p. 27) como valorização de uma visão mais complexa da linguagem e os inúmeros recortes que podem ganhar espaço nas discussões das disciplinas, que sugerimos aqui a Toponímia na intenção de colocar em evidência a maneira como os nomes dos lugares influenciam e são influenciados pela vida cotidiana. Nessa pretensão de introduzir a Toponímia nas aulas de língua portuguesa, destacando seu caráter interdisciplinar, é conveniente destacarmos os aspectos teórico-metodológicos desse campo de estudo.

\section{TOPONÍMIA: ASPECTOS TEÓRICOS E METODOLÓGICOS}

Como já assinalamos anteriormente, a Toponímia se ocupa do estudo da motivação e significado dos nomes dos lugares. Deve ser concebida a partir do ato da nomeação que, segundo Dick (1990), é uma das atividades humanas mais significativas, especialmente porque reflete a compreensão do homem acerca da sua realidade, de modo que

[...] o homem, em sua qualidade de membro de um agrupamento, representa, por força da introjeção de costumes e de hábitos generalizados, senão integralmente, pelo menos uma parcela significativa do pensamento coletivo. É a resultante de uma modelagem constantemente burilada pelo próprio dinamismo das paralelas línguo-sociológicas em que se movimenta. Suas ideias e manifestações de espírito, suas atitudes e condutas conscientizadas, ou não, diante de situações concretas reguladas pela necessidade humana de sobrevivência - e seu próprio existir, enfim, tornam-no a "personalidade histórica" atemporal e a espacial, por excelência (DICK, 1990, p. 30).

Os estudos toponímicos engajam em seus aportes teóricos todos esses pontos destacados por Dick (1990), que, em suma, estão se referindo aos aspectos linguísticos e "línguo-sociológicos", tratando com pertinência os diversos fatores de cunho social, cultural, religioso, político etc., quando relacionados aos nomes dos lugares.

Quando a Toponímia alude temas como os que citamos há pouco, torna-se, impreterivelmente, um campo de pesquisa interdisciplinar que valoriza as contribuições, olhares, concepções e abordagens de outros campos do saber e, assim, ela se mostra como 
temática ideal para atividades no compêndio de competências curriculares da disciplina Língua Portuguesa, pois, nas Orientações Curriculares para o Ensino Médio, sugere que

[...] nesse campo de estudo, praticamente se impõe a necessidade da abordagem interdisciplinar, quer no que toca aos referenciais teórico-metodológicos abraçados pela Língua Portuguesa para o tratamento do texto nas atividades de compreensão e produção, quer no que se refere à teia de relações entre as disciplinas do ensino médio para o alcance das finalidades da educação com as quais se compromete nesse nível de ensino (BRASIL, 2006, p. 34).

É importante esclarecermos que, “[...] embora seja evidente a importância dos estudos toponímicos, uma vez que sua característica interdisciplinar favorece a aquisição de múltiplos conhecimentos, sua aplicação tem ficado restrita, quando muito, às academias" (SOUSA, 2013, p. 1). Reiteramos, assim, a inserção de atividades voltadas para as aulas de língua portuguesa que incluam a abordagem da Toponímia.

Durante o curso do ensino médio, espera-se que o estudante possa "[...] atuar, de forma ética e responsável, na sociedade, tendo em vista as diferentes dimensões da prática social" (BRASIL, 2006, p. 18). Ressaltamos que a Toponímia deve ser entendida como prática social por ser uma atividade desempenhada pelo homem o que, mais uma vez, condiz com as Orientações Curriculares Para o Ensino Médio.

Acerca desse aspecto, é importante citarmos Dick (1987) quando reflete sobre o seguinte:

Que faz, então, este homem dentro dos nossos estudos? É ele quem traz, para os designativos geográficos, a verdadeira psicologia popular, paralelamente ao agir oficial ou sistemático, enfocando, quantas vezes, o que de mais significativo oferece a região [...] (DICK, 1987, p. $3)$.

Desse modo, entendemos que o lugar do homem nos estudos toponímicos é de caráter central e, nesse sentido, notamos, de igual modo, que os ambientes nos quais o homem está envolvido e sua maneira de ver o mundo são fatores que estão sempre presentes na concepção do espaço e, consequentemente, na sua nomeação.

Centralizando esses fatores, nesse momento, torna-se importante referenciarmos alguns pontos essenciais para um estudo toponímico. Para tanto, precisamos tratar os nomes de lugar com uma nomenclatura específica, eles devem ser tratados como topônimos. É preciso partir de documentos auxiliares de trabalho: as cartas topográficas, onde podemos selecionar os topônimos a serem analisados em uma pesquisa.

É preciso dizer também que, no Brasil, a toponímia parte de um modelo taxionômico de classificação elaborado por Dick (1987), que leva em consideração a natureza dos topônimos (como são referidos os nomes dos lugares). Essa natureza pode ser física, quando os topônimos têm características ligadas aos aspectos físicos do lugar, ou antropocultural, quando esses designativos estão ligados a representações dos aspectos da vida humana nos vários âmbitos. Há, nas duas naturezas citadas, uma motivação para a escolha dos designativos de lugar. Abaixo, apresentamos dois quadros, com o aporte de Dick (1986), que contêm uma sistematização da classificação proposta por esse autor: 


\begin{tabular}{|c|c|c|}
\hline $\begin{array}{c}\text { Classificação } \\
\text { toponímica }\end{array}$ & Definiçãa & Exemplo \\
\hline Astrotopônimo & $\begin{array}{l}\text { Topônimo referente aos nomes dos } \\
\text { corpos celestes. }\end{array}$ & Saturno - ES \\
\hline Cardinotopônimo & $\begin{array}{l}\text { Topônimo referente às posições } \\
\text { geográficas em geral. }\end{array}$ & Lagoa do Sul-SC \\
\hline Cromotopônimo & Topônimo referente às cores. & Rio Pardo - SP \\
\hline Dimensiotopônimo & $\begin{array}{lcc}\text { Topônimo } & \text { referente } & \text { às } \\
\text { características do acidente. }\end{array}$ & Riacho Grosso-SE \\
\hline Fitotopônimo & $\begin{array}{l}\text { Topônimo referente aos nomes de } \\
\text { vegetais. }\end{array}$ & Pinheiral-RJ \\
\hline Geomorfotopônimo & $\begin{array}{l}\text { Topônimo referente } \\
\text { às formas } \\
\text { topográficas } \\
\text { litorâneas. }\end{array}$ & Costa rica - MT \\
\hline Hidrotopônimo & $\begin{array}{l}\text { Topônimo referente aos acidentes } \\
\text { hidrográficos. }\end{array}$ & Foz do Riozinho - $A M$ \\
\hline Litotopônimo & $\begin{array}{l}\text { Topônimo de índole mineral, } \\
\text { relativos à constituição do solo. }\end{array}$ & Pedreiras - $M G$ \\
\hline Meteorotopônimos & $\begin{array}{l}\text { Topônimo referente aos fenômenos } \\
\text { atmosféricos. }\end{array}$ & Riacho das Neves - BA \\
\hline Morfotopônimos & $\begin{array}{l}\text { Topônimo referente aos sentidos e } \\
\text { formas geométricas. }\end{array}$ & Triângulo-MT \\
\hline Zootopônimos & Topônimo de índole animal. & Vacaria - RS \\
\hline
\end{tabular}

Quadro 01: Classificação dos topônimos de natureza física

Fonte: Dick (1986, p. 38-39).

\begin{tabular}{|c|l|c|}
\hline $\begin{array}{c}\text { Classificação } \\
\text { toponímica }\end{array}$ & \multicolumn{1}{|c|}{ Definição } & Exemplos \\
\hline $\begin{array}{c}\text { Animotopônimo (ou } \\
\text { Nootopônimo })\end{array}$ & $\begin{array}{l}\text { Topônimo referente à vida psíquica } \\
\text { e à cultura espiritual. }\end{array}$ & Triunfo-AC \\
\hline Antropotopônimo & $\begin{array}{l}\text { Topônimo referente aos nomes } \\
\text { próprios e individuais. }\end{array}$ & Fernão Velho-AL \\
\hline Axiotopônimos & $\begin{array}{l}\text { Topônimo referente aos títulos è̀s } \\
\text { dignidades. }\end{array}$ & Doutor Pedrinho-SC \\
\hline Corotopônimos & $\begin{array}{l}\text { Topônimo referente aos nomes de } \\
\text { cidades, países, regiões ou }-B A \\
\text { continentes. }\end{array}$ & Nova Viçosa $-\mathrm{BA}$ \\
\hline Cronotopônimos & $\begin{array}{l}\text { Topônimo referente às indicações } \\
\text { cronológicas. }\end{array}$ & Ocauçu-SP \\
\hline Ecotopônimos & $\begin{array}{l}\text { Topônimo referente às habitações } \\
\text { de modo geral. }\end{array}$ & Relógio $-P R$ \\
\hline Ergotopônimo & $\begin{array}{l}\text { Topônimo referente aos elementos } \\
\text { da cultura. }\end{array}$ \\
\hline
\end{tabular}




\begin{tabular}{|c|c|c|}
\hline Etnotopônimos & $\begin{array}{l}\text { Topônimo referente aos elementos } \\
\text { étnicos isolados. }\end{array}$ & Rio Xavante - MT \\
\hline Dirrematotopônimo & $\begin{array}{l}\text { Topônimo constituído de frases ou } \\
\text { enunciados linguísticos. }\end{array}$ & Valba-me Deus- $M A$ \\
\hline Hierotopônimo & $\begin{array}{l}\text { Topônimo referente aos nomes } \\
\text { sagrados. (Hagiotopônimo, quando } \\
\text { há referência aos santos e santas do } \\
\text { hagiológio romano; e Mitotopônimo } \\
\text { quando há referência às entidades } \\
\text { mitológicas). }\end{array}$ & $\begin{array}{l}\text { Cruzes - PE; } \\
\text { São Pedro-SC } \\
\text { (bagiotopônimo) } \\
\text { Curupira - AM } \\
\text { (Mitotopônimo) }\end{array}$ \\
\hline Historiotopônimo & $\begin{array}{l}\text { Topônimo referente aos } \\
\text { movimentos histórico-sociais e aos } \\
\text { seus membros. }\end{array}$ & Independência- $A C$ \\
\hline Hodotopônimo & $\begin{array}{l}\text { Topônimo referente às vias de } \\
\text { comunicação rural ou urbana. }\end{array}$ & Córrego do Atalho - GO \\
\hline Numerotopônimos & $\begin{array}{l}\text { Topônimo referente aos adjetivos } \\
\text { numerais. }\end{array}$ & Duas Pontes - RO \\
\hline Poliotopônimos & $\begin{array}{l}\text { Topônimo constituído pelos } \\
\text { vocábulos aldeia, vila, povoação, } \\
\text { arraial. }\end{array}$ & Rio da Cidade - RJ \\
\hline Sociotopônimo & $\begin{array}{l}\text { Topônimo referente às atividades } \\
\text { profissionais ou a ponto de } \\
\text { encontros. }\end{array}$ & Oficina - MG \\
\hline Somatopônimos & $\begin{array}{l}\text { Topônimos referentes às relações } \\
\text { metafóricas das partes do corpo } \\
\text { humano ou animal. }\end{array}$ & Rio da Mão Esquerda - AL \\
\hline
\end{tabular}

Quadro 02: Classificação dos topônimos de natureza antropocultural

Fonte: Dick (1986, p. 39-40)

A classificação delineada por Dick (1986), como a própria pesquisadora destaca, não está finalizada, pois os topônimos possuem motivações diversas. Assim, a autora destaca que essa classificação pode ganhar acréscimos e subdivisões. Para os animotopônimos, Isquerdo (1996) traz uma subclassificação: animotopônimos eufóricos (se o animotopônimo apresentar uma conotação positiva. Ex.: Harmonia) e disfóricos (se o animotopônimo tiver uma índole negativa. Ex.: Inveja). Para os hagiotopônimos, Lima (1998) propõe uma divisão que compreende os hagiotopônimos autênticos e aparentes. Os autênticos para os casos de denominativos que se remetem a entidades religiosas (São Miguel dos Campos - AL) e os aparentes para os casos em que os nomes religiosos têm um fundo político (Sítio São Luiz - aqui a referência não é um santo canonizado, mas um padre). Na contribuição de Francisquini (1998), encontramos os acronimotopônimos, referentes às siglas; e os estamatotopônimos, que se referem aos sentidos; os grafematopônimos são aqueles formados por letras do alfabeto; os higietopônimos estão relacionados à higiene, à saúde; e os necrotopônimos, que fazem referência ao que está morto, a restos mortais. 
Nesse conhecimento básico da metodologia da Toponímia, contemplando esse processo de seleção e classificação dos topônimos, há a orientação de um trabalho sistemático a partir da ficha lexicográfico-toponímica. Em Dick (2004), encontramos itens como a localização do topônimo (estado, município, bairro), o topônimo (e o nome popular, se houver), designativos anteriores, tipo de acidente geográfico que pode ser físico (F) e/ou humano $(\mathrm{H})$, classificação taxionômica e natureza (física e/ou antropocultural), etimologia, histórico, contexto, fontes (bibliográficas), nome(s) do(s) pesquisador(es), data da coleta.

Trabalhar com os topônimos exige, ainda, um tratamento linguístico da estrutura morfossintática e da composição semântica. Quanto à estrutura morfossintática, devemos considerar, segundo Dick (1987), que há topônimos com uma estrutura simples, formados por apenas uma palavra, (ex.: Cruzes, PE); há topônimos compostos, aqueles formados por duas ou mais palavras e elementos linguísticos de procedências variadas (ex.: Cruz das Posses, SP); e ainda os híbridos, topônimos formados a partir de palavras de várias línguas (Araticumirim, PA). Quanto à composição semântica, podemos recorrer às categorias taxionômicas apresentadas há pouco nos quadros 1 e 2 .

Além dos aspectos relacionados à Toponímia, cabe tecermos algumas considerações sobre a memória, uma vez que será um dos elementos fundamentais que compõem o cerne desta proposta que apresentamos.

\section{A MEMÓRIA}

Memória, para Ferreira (1988, p. 427), pode ser entendida como a “[...] faculdade de reter as ideias, impressões e conhecimentos [...]". Meihy (2000), por sua vez, afirma que memória é uma organização subjetiva de lembranças, que pode ser individual e coletiva. Partindo disso, damos destaque à memória oral, refletindo que

\footnotetext{
Não se pode esquecer que, mesmo no caso daqueles que dominam perfeitamente a escrita e nos deixam memórias ou cartas, o oral nos revela o "indescritível", toda uma série de realidades que raramente aparecem nos documentos escritos, seja porque são consideradas "muito insignificantes" - é o mundo da cotidianidade - ou inconfessáveis, ou porque são impossíveis de transmitir pela escrita. É através do oral que se pode apreender com mais clareza as verdadeiras razões de uma decisão; que se descobre o valor das malhas tão eficientes quanto as estruturas oficialmente reconhecidas e visíveis [...] (JOUTARD, 2000, p. 33-34).
}

Joutard (2000) tece considerações acerca das diferentes concepções da escrita e da oralidade, dando destaque à memória oral, que nos interessa para a exposição desta proposta, sobretudo porque tomamos o relato oral, o "indescritível" da vida cotidiana, como importante, uma vez que ele também pode dar significado aos nomes dos lugares, já que Dick (1986) afirma que os designativos de lugar trazem, em sua gênese, aspectos da vida do homem. E quando direcionamos para a motivação da escolha dos nomes dos lugares, a oralidade pode nos dar uma concepção mais aproximada da vida cotidiana das pessoas. 
Na contemplação desses pontos, à memória também está atribuída a capacidade de ressignificação dos fatos do passado no presente, como nos explica Rossi (2010) ao falar da memória em relação ao tempo

O tempo possui uma direção e uma flecha. Escorre de alguma coisa para outra coisa. $\mathrm{Na}$ visão linear do tempo, é proibida qualquer repetição. Trabalha-se somente com eventos singulares, individuais, não repetíveis, cada um se posicionando num ponto determinado da flecha. Porém, muitos afirmaram que pedaços do passado se reapresentam no presente, dando lugar a renascimentos ou a retornos. Na ideia do retorno está implícita a de uma volta e de uma repetição, de uma não unicidade e não repetibilidade dos eventos, de possíveis uniformidades ou leis do devir. A metáfora da flecha se mistura, de modos imprevistos e complicados, à do ciclo (ROSSI, 2010, p. 129-130).

A memória, então, é "“[... entendida como possibilidade de se referir a um passado dotado de sentido: algo que pode opor barreiras sólidas aos processos de laminação, quebra, isolamento, erradicação do ambiente e do passado de indivíduos e de comunidades" (ROSSI, 2010, p. 206). Vemos, mediante o apontamento de Rossi (2010), que há, indiscutivelmente, muito a ser contemplado a partir da memória, e isso traz a possibilidade de, cada vez mais, travarmos um diálogo entre sujeitos, com suas "diferenças culturais", termo de Portelli (2010), que vai perpassar vários processos sociais, interessando-nos, no momento, o processo de ensino-aprendizagem.

Desse modo, concordamos com Passerini (2011) ao dizer que a memória oral sugere subjetividade e intersubjetividade, assim como a postura interdisciplinar que, como expomos anteriormente, é de grande valia no âmbito do ensino e que, por sua vez, está presente nos aspectos teórico-metodológicos da Toponímia.

Assim, respaldados pelos apontamentos expostos acima, sobre Toponímia e memória, podemos apresentar uma sugestão metodológica para a aplicação da Toponímia nas aulas de língua portuguesa.

\section{PROPOSTA DE ATIVIDADE NA SALA DE AULA}

Considerando o viés da presente proposta para a sala de aula, que consiste em uma relação entre toponímia e memória e que perpassa a interdisciplinaridade, é preciso delimitarmos o tipo de pesquisa e os passos metodológicos a serem discutidos com os estudantes por mediação do professor. Desse modo, fazemos menção à pesquisa de campo, pois, como mostram Prodanov e Freitas (2013), essa modalidade consiste, entre outros elementos, na ida do pesquisador ao lugar em que se identificou o fenômeno.

Prezamos, portanto, pela pesquisa de abordagem qualitativa e, como métodos de coletas de dados, propomos a entrevista com um questionário pré-estabelecido, isto é, o momento da entrevista será conduzido a partir de perguntas selecionadas anteriormente acerca do tema. Porém, não deve acontecer uma entrevista em que o entrevistado apenas responda o que for perguntado de modo "mecânico", mas deve acontecer um momento de conversa no qual a narrativa, a partir da memória das pessoas entrevistadas, tenha centralidade. Assim, os alunos poderão fazer perguntas acerca dos nomes dos lugares e, 
como se estivessem ouvindo uma mera história, poderão visualizar a riqueza que há no estudo dos topônimos (a história do lugar, os nomes que o lugar já teve, as razões políticas e religiosas, por exemplo, envolvidas na motivação para o nome etc.).

Primeiramente, alunos e professor devem pensar em uma localidade para a atividade. Isso, evidentemente, dependerá da realidade local de cada escola e também do tempo disponibilizado para a realização dessa atividade. Nas áreas urbanas, podem ser escolhidos bairros e ruas, por exemplo. Nos espaços rurais, pode-se pensar em igarapés, vicinais, colocações, comunidades tradicionais etc..

$\mathrm{O}$ intuito de obter informações para a pesquisa com pessoas que guardem memórias sobre a rua ou o bairro escolhido, o critério principal para a seleção delas, deve ser o tempo de residência no local. Pensamos, então, nas pessoas adultas, mais velhas, que tenham mais de dez anos de residência no local escolhido para a pesquisa.

Escolhendo essas pessoas como informantes, destacamos a memória oral como método principal de coleta de dados. Acreditamos que o trabalho com os indivíduos que moram no local que será escolhido pela turma pode partir da memória oral como instrumento de coleta de dados, pois as impressões, as ideias e os conhecimentos dos moradores se colocam como peças fundamentais para o entendimento do contexto do topônimo e, consequentemente, para a compreensão da motivação que levou à escolha do designativo.

Será, desse modo, um momento de conversa, de interação, de exercício e, principalmente, de curiosidade para os alunos. É preciso termos em mente que "[...] a diferença cultural entre pesquisador e narrador sujeita este último a estímulos imprevistos, força-o a explorar setores e aspectos da sua experiência que geralmente não são mencionados quando ele conta histórias ao seu círculo imediato" (PORTELLI, 2010, p. 20); e nessas condições, os alunos farão com que as pessoas entrevistadas, os narradores, tenham destaque no processo, uma vez que são elas que apresentarão, de forma narrada, a motivação para a escolha dos nomes, ou mesmo, farão referência aos pais, aos avós, a outros moradores antigos que contaram a história do lugar que vai se reproduzir. Em outras palavras, os alunos estarão dispostos a ouvir o que está sendo narrado por aquelas pessoas que já passaram por um processo que rememora lembranças, datas, comemorações e os nomes dos lugares dotados de sentido.

\section{PASSOS PARA A EXECUÇÃO DA METODOLOGIA}

Realizada a discussão acerca da proposta e sobre Toponímia e memória, é interessante elaborar um roteiro para a atividade que compreenderá, em um primeiro momento, o espaço da sala de aula e, em seguida, a localidade escolhida para o trabalho de campo. Esboçamos, a seguir, algumas sugestões que podem auxiliar o professor em seu trabalho de mediação desse processo.

\subsection{NA SALA DE AULA:}


a) Discussões sobre o tema e familiarização com os termos específicos da Toponímia; a metodologia (fichas lexicográfico-toponímicas, taxionomias);

b) Discussão da proposta (objetivos), dos passos metodológicos (dentro e fora da sala de aula);

c) Escolha do lugar (rua, vila, bairro etc.);

d) Divisão da turma de alunos em equipes para a execução da sondagem, de modo que cada equipe possa escolher um bairro;

e) Sondagem para a seleção dos informantes: estabelecimento dos critérios de seleção dos informantes (ou os moradores mais antigos) que residem no bairro. É importante ter um mapa do lugar escolhido;

f) Elaboração do roteiro para a entrevista (sugestões): Primeiramente, a identificação do informante (pessoa entrevistada): Nome, idade, profissão, tempo de residência no bairro. Sobre o lugar: Qual o nome do bairro? Da rua? $\mathrm{O}$ (a) senhor (a) pode nos contar um pouco da história do bairro? $\mathrm{O}$ (a) senhor (a) sabe por que o bairro é chamado por esse nome? $\mathrm{E}$ a rua? $\mathrm{O}$ bairro tem (ou já teve) outro nome?

\subsection{ATUAÇÃO EM CAMPO APÓS A SONDAGEM:}

a) Visita à casa dos informantes selecionados com o intuito de lançar o convite para a participação na atividade e realizar as entrevistas;

b) Apresentação da equipe, do tema, do objetivo, e como procederá a entrevista;

Observação 1: É preciso deixar o entrevistado à vontade quanto à forma de linguagem e à maneira que ele escolher para proceder no momento da entrevista, ou seja, ele pode não começar sua fala contemplando a primeira pergunta do questionário, por exemplo, e isso não deve ser um problema. Já que se trata de um momento de interação e de conversa também, os alunos podem retomar o assunto de outro ponto do questionário quando o informante abrir um espaço;

c) Realização das entrevistas;

Observação 2: Outra característica desse tipo de pesquisa são os materiais. Como estamos discutindo uma proposta como essa, que versa sobre a ida a campo, é necessário pensar em materiais como pranchetas, canetas, questionários impressos, folhas para anotações e gravador de áudio. A maneira escolhida para o armazenamento dos dados fica a critério do professor e dos alunos. Sugerimos aqui o questionário, preenchido a partir da memória dos entrevistados, e também, se for possível, a utilização do gravador de áudio, o que pode deixar os alunos com mais liberdade para fazer comentários e perguntas durante a entrevista bem como a pessoa escolhida para cedê-la.

Ao término do trabalho de campo, quando o professor solicitar aos alunos um trabalho por escrito que apresente os resultados da pesquisa feita em campo, para produzir 
um documento de registro dos resultados alcançados. É interessante, ainda, fazer exposição oral dos trabalhos entre as equipes em sala de aula. Trata-se de um momento de conversa entre as equipes e o professor.

$\mathrm{Na}$ culminância do projeto, poderão ser confeccionados banners com os tópicos principais da pesquisa e seus resultados, com o objetivo de divulgar para a comunidade escolar e para a comunidade externa o registro toponímico e sua relação com a memória dos moradores.

\section{CONSIDERAÇÕES FINAIS}

Propostas de atividades incluindo a Toponímia nas aulas de Língua Portuguesa como também discussões acerca do caráter interdisciplinar da Toponímia têm sido feitas. Citamos aqui os trabalhos de Sousa (2013), que já propunha um modelo de atividade com o viés da Toponímia para o ensino básico; Nunes e Andrade (2015), que fazem considerações sobre a Toponímia no contexto do ensino, e Melo (2015), que discute os nomes de lugares na obra lexicográfica de uso escolar.

A proposta que apresentamos para as aulas de língua portuguesa para alunos do ensino médio tange a possibilidade de aproximar os estudos toponímicos, a prática na sala de aula e a pesquisa de campo. À medida que os estudantes se interessem e se comprometam com a ideia, eles podem visualizar uma possibilidade de interação entre vários campos do conhecimento. Pode-se consultar um professor de geografia, por exemplo, para pedir uma orientação no que se refere à localização do local escolhido, um conhecimento prévio sobre os mapas; um professor de história pode oferecer um acompanhamento no trabalho de campo, por se tratar de uma perspectiva que trabalha com a história dos nomes apreciada a partir da memória dos moradores do lugar, e ainda outras coisas.

A interdisciplinaridade, enquanto postura diante do processo de ensinoaprendizagem, encaixa-se com perfeição naquilo que a Toponímia tem a oferecer. Um campo de estudo interdisciplinar que toma os nomes de lugares como objeto de pesquisa oferece, ao mesmo tempo, diferentes olhares acerca desses nomes, trazendo, por vezes, um trabalho focado na etimologia, no significado dos designativos, na motivação, na arqueologia dos nomes, na sua importância para a geografia, para a história, entre outras áreas.

Para os estudantes do Ensino Médio, esta seria uma proposta que pode aproximar a teoria aplicada em sala de aula com a experiência de uma pesquisa de campo (ainda que inicial) que proporcione um contato com a língua em uso, no léxico de uma comunidade de pessoas que falam sobre a história de um bairro, de uma rua, de um ramal, vicinal etc.; dando ênfase aos topônimos.

A memória oral, portanto, dentro do desenho metodológico da pesquisa de campo, tende a proporcionar, como preconiza As Orientações Curriculares Para o Ensino Médio, uma interação que envolva respeito pelo outro, trabalho em equipe, dinamicidade na discussão de teoria e prática e, sobretudo, um gênero textual oral (a narrativa da memória) por meio do qual se discuta a língua a partir dos topônimos. 


\section{REFERÊNCIAS}

DICK, Maria Vicentina de Paula do Amaral. Toponímia e antroponimia no Brasil. Coletânea de estudos. São Paulo - SP: Impresso pelo Serviço de Artes Gráficas da Faculdade de Filosofia, Letras e Ciências Humanas / USP, 1986.

DICK, Maria Vicentina de Paula do Amaral. A motivação toponímica e a realidade brasileira. São Paulo: Arquivo do Estado, 1990.

DICK, Maria Vicentina de Paula do Amaral. Rede de conhecimento e campo lexical: Hidrônimos e hidrotopônimos na onomástica brasileira. In: ISQUERDO, Aparecida Negri; KRIEGER, Maria da Graça. (orgs). As ciências do léxico: Lexicologia, Lexicografia e terminologia. Campo Grande: UFMS, 2004, p. 121-130.

FERREIRA, Aurélio Buarque de Holanda. Dicionário Aurélio básico da língua portuguesa. Rio de Janeiro: Nova Fronteira, 1988.

FRANCISQUINI, Ignez de Abreu. O nome e o lugar: Uma proposta de estudos toponímicos da microrregião de Paranavaí. 1998. 255p. Dissertação. Universidade Estadual de Londrina, Londrina, 1998.

ISQUERDO, Aparecida Negri. O fato linguistico como recorte da realidade sócio-cultural. 1996, 409 p. Tese. Universidade Estadual Paulista, São Paulo, 1996.

JAPIASSU, Hilton. Interdisciplinaridade e patologia do saber. Rio de Janeiro: Imago, 1976.

JOUTARD, Philippe. Desafios à história oral do século XXI. In: FERREIRA, Maneta de Moraes; FERNANDES, Tania Maria; ALBERTI, Verena (orgs). História oral. Desafios para o século XXI. Rio de Janeiro: Fiocruz, 2000.

LIMA, Ivone Alves. A motivação religiosa nos topônimos paranaenses. In: Seminário do grupo de estudos linguísticos do Estado de São Paulo, 45, Campinas, 1997. GEL/UNESP, 1997, v. 1, p. $422-428$.

MEIHY, José Carlos Sebe Bom. Manual de história oral. 3. ed. São Paulo: Loyola, 2000.

MELO, Pedro Antônio Gomes de. A obra lexicográfica de uso escolar: O léxico toponímico e o dicionário pedagógico de língua portuguesa. In: Cadernos do CNLF, Vol. XIX, v. 2. Rio de Janeiro: CiFEFiL, 2015.

NUNES, Verônica Ramalho, ANDRADE, Karylleila dos Santos. Toponímia na perspectiva da teoria da interdisciplinaridade: Breves considerações no contexto do ensino. Cadernos do CNLF, Vol. XIX. Rio de Janeiro: CIFEFIL, 2015.

PASSERINI, Luisa. A memória entre política e emoção. Tradução Ricardo Santhiago. São Paulo: Letra e Voz, 2011.

PORTELLI, Alessandro. Ensaios de história oral. Tradução Fernando Luiz Cássio e Ricardo Santhiago. São Paulo: Letra e Voz, 2010. 
PRODANOV, Cléber Cristiano; FREITAS, Ernani César de. Metodologia do Trabalho Científico: Métodos e Técnicas da Pesquisa e do Trabalho Cientifico. $2^{\mathrm{a}}$ ed. Rio Grande do Sul: Universidade FEEVALE, 2013.

ROSSI, Paolo. O passado, a memória, o esquecimento. Seis ensaios da história das ideias. Tradução Nilson Moulin. São Paulo: Editora UNESP, 2010.

SOUSA, Alexandre Melo de. Para a aplicação da toponímia na escola. Cadernos do CNLF, vol. XVII, n.02. Rio de Janeiro: CiFEFiL, 2013.

TRINDADE, Diamantino Fernandes. Interdisciplinaridade: Um novo olhar sobre as ciências. (65-83) In: FAZENDA, Ivani. O que é interdisciplinaridade? São Paulo: Cortez, 2008. 